\title{
The Effect of Swain's Push Out Hypothesis on Promoting Jordanian Language Learners' Reading Performance
}

\author{
Abeer Al-Ghazo ${ }^{1}$, Issam Taamneh ${ }^{2 *}$ \\ ${ }^{1}$ Ajloun National University, Ajloun, Jordan \\ ${ }^{2}$ Tabuk University-Tabuk, KSA
}

Corresponding Author: Issam Taamneh, E-mail: dr.essamtaamneh@gmail.com

\section{ARTICLE INFO}

\section{Article history}

Received: August 14, 2017

Accepted: October 19, 2017

Published: January 05, 2018

Volume: 7 Issue: 1

Advance access: December 2017

Conflicts of interest: None

Funding: None

\begin{abstract}
The present study investigates the effect of push out hypothesis in language acquisition that is based on Swain's push out hypothesis (1985) on promoting Jordanian language learners' reading performance. The sample of the study consists of two classes of English reading comprehension Course, Level one with 60 EFL students, 30 in the control group and 30 in the experimental group. Those students were belonging to the Department of English Language and Literature. The researchers choose the reading texts from reading comprehension course which was published by Macmillan Education LTD, intermediate level (2001). The researchers construct a multiplechoice reading comprehension test to assess the students reading comprehension. The participants in the two groups took a vocabulary test and an achievement reading comprehension test as a pre-test in order to be sure that the participants formed a homogenous sample. The experimental group underwent a treatment based on Swains' push out task, while the control group did not receive any treatment. Then, Proper statistical analyses were used to analyze the results. The scores of control and experimental group were compared at the end of the treatment period. The results reveal that the scores of the experimental group on the post-test were significantly higher than those of the control group. These results prove that teaching on the basis of the Swains' push out hypothesis was successful to develop the students' reading comprehension as well as their performance.
\end{abstract}

Key words: Push Out Hypothesis, Reading Comprehension, Reading Skill.

\section{INTRODUCTION}

Nowadays, English is considered a universal language. It is the language that all learners try to learn and master. Learners and students who want to learn English must be able to master the four English skills: Reading, speaking, writing and listening. The integration of the four skills is necessary in the learning process. Students should be effective learners through their participation, interaction and doing the push out tasks in the proper way. Reading skill, as one of the four English skills, plays an essential role in the acquisition of English as a foreign language. It is a crucial skill for educators and teachers to ensure that learners acquire adequate vocabulary to be able to read and comprehend any text very well. Reading comprehension depends on many components such as vocabulary, grammar, cohesion and coherence of ideas, pronunciation, spelling ....etc. These components are essential in language acquisition. However, there is a complex dynamic relation between reading comprehension ability and vocabulary size (Hu \& Nation, 2000). ". "without vocabulary nothing can be conveyed" Wilkins (1972) (pp. 111-112).Vocabulary is a key component to English lan- guage teaching because without those sufficient vocabulary, our learners cannot express their own ideas and feelings. The shortage in vocabulary for EL learners will definitely lead to a lack of communication among the speakers, which is a major problem in mastering the language.

Vocabulary acquisition is a vital component in language-learning and language teaching that has to be considered in enhancing reading and writing comprehension, even the knowledge of English grammar. Laufer and Sim (1985) claimed that in order to acquire a foreign language, learners need to have sufficient vocabulary, and subject matter knowledge, and syntactic structure. Nagy, Herman and Anderson (1985), and Nagy and Herman (1987) indicated that vocabulary is the major facilitator of reading. It helps learners in understanding the text in a proper way. Learners, who have a good storage of vocabulary, are expected to achieve better grades in their studying.

There is no doubt that reading comprehension related directly to the vocabulary knowledge of learner's language. Anderson and Freebody (1981) state that in order to assess how well that reader understands the text, it is important to know the general vocabulary knowledge of the reader. Nagy 
and Herman (1987) state that teachers should show up the students to extensive reading, that lead to vocabulary growth because vocabulary is seen as a vital facilitator of reading performance (Nagy, Herman and Anderson, 1985; and Nagy and Herman 1987).In his study, Laufer's (1992) finds that students who have less than 3000 word families could not read well regardless of their academic abilities, while students with vocabulary sizes of more than 5000 could read well in their L2.

The National Reading Panel(2000) (NRP) described reading comprehension as

" a complex process and it is an intentional thinking during which meaning is constructed through interactions between text and reader. The content of meaning is influenced by the text and by the reader's prior knowledge and experience that are brought to bear on it "(pp. 4-5).

NRP stated that there are three major factors affect reading comprehension. Firstly, vocabulary instruction which has an important role in reading comprehension as a cognitive and interactive process.Secondly, active interactive strategic processes. The active interaction that takes place between learners and their teachers will lead to a better learning and understanding. Thirdly, the preparation of teachers who are the main facilitator in the interactive strategic processes to develop the reading comprehension of their students. It necessary for all teachers to prepare their teaching subjects in a good way as it helps in facilitating the learners' comprehension to the subjects they are learning. It is known that good preparation will definitely lead to a better participation from all learners. Reading comprehension strategies are of great value and concern. Strategies are very important to overcome the comprehension problems and obstacles, help readers comprehend the text, engage them meaningfully with the text, and then they become good readers and recipient.

Swain (1985) states that:

"To achieve native-speaker competence, the meaning of 'negotiating meaning' needs to be extended beyond that usual sense of simply 'getting one's message across'. Simply getting one's message across can and does occur with grammatically deviant forms and sociolinguistically inappropriate language" (p.248).

Many researchers (Gass, 1997; Pica, 1994) have argued that second language or foreign language learners develop grammatical accuracy in their second language through 'negotiation of meaning' because they maintain that comprehensible input, which was developed by Krashen 1980 (what Krashen calls "I + 1 input", is not enough for L2 acquisition and learning. Despite there is a general agreement among researchers that comprehensible input is a vital component of source language acquisition (SLA), most have confirmed that comprehensible input for L2 instruction is insufficient. Long (1996) states that the best way to help L2 or foreign learners to be native speaker competence is to engage them in negotiation of meaning. When students are engaged in the learning process, it is expected that it will facilitate their learning.

Swain uses many terms related to the comprehensible output, like 'negotiated output', 'pushed output' or just 'out- put' or output hypothesis, to help students to understand language that contains grammar and vocabulary through the help of contextual clues, and knowledge of the meaning of words. Swain strongly pointed out the role of push out hypothesis as a sufficient factor for language acquisition

Swain states that language acquisition needs to incorporate the notion of being 'pushed' toward the delivery of a message that is conveyed coherently, and appropriately. This act of "pushing asks learners to make more of an effort that forces them to process language more deeply and efficientl . Learners are encouraged to reproduce language from a text with many output tasks and activities such as the dictogloss (Swain, 2000). According to her, it is the best way to test the one's linguistic knowledge by using that knowledge in some productive ways; whether it is teaching a concept to someone or writing program. While in the case of language learning, using the linguistic knowledge by getting a simple idea across, or modifying a previous utterance.

The researchers claim that when learners are pushed to produce language and to deliver the message effectively, they may notice the linguistic forms in the input and thus the successful learning may happen as a result. Learners have to believe that vocabulary is very important in the process of comprehending texts. It is very important to engage students in the output activities which are considered as a useful facilitator to acquire the language and to achieve the language competence. So in order to comprehend any text, learners have to increase their vocabulary growth. Leeser, (2008) indicate that pushed output can induce the learners to process input effectively.

The importance of Push Out Hypothesis which was proposed in 1985 has been examined by many researches. Kowal \& Swain (1997), observe that students who working on three different types of collaborative tasks (dictogloss, cloze, and proof-reading) in a French immersion program. They notice the gap between what students wanted to say and what they were able to say. This happened primarily as students were "pushed" to produce the language. Students should be encouraged to use and push out the language otherwise; they will not be able to master it. In doing such a strategy it is expected to achieve the expected learning outcomes.

Shekary (2004) conducts a study to examine the role of negotiation of meaning and noticing in SLA development on cyber space. The results of her study show that noticing became better when it took place in online negotiations. Moreover, she notices that the occasions of noticing were better than those in offline settings. Izumi and Bigelow (2000), and Izumi et al. (1999) investigate the effects of output on the learners' subsequent noticing of as well as focusing on subsequent input. They discovered that learners achieved obvious development if the learners are put in real life output situations. Izumi (2002) suggests that when learners are encouraged to produce output they will be able to get better results in learning L2 than those learners who are not given that chance to produce enough output. The more they are encouraged to use the language, the more they are going to learn and master it. Students should be put in real situations to encourage them to use the output in an effective and useful way. 
Zhang (2009), and in order to develop the oral fluency in the EFL context, tries to shed the light on the importance and the role of input, interaction and output from both theoretical and empirical points of view. To achieve the purpose of the study, two instruments were used: tests of oral fluenc and face-to-face interviews. The findings of the study reveal that it is possible for non-native to develop their oral fluenc through efficient and effective input, interaction and output in EFL. Moreover, he asks the following question: "Why did the most Chinese English learners fail to speak English fluen ly?" He finds that many reasons could stand against speaking English fluently such as the lack of effective input and output, the lack of desire to interact with others. Moreover, he find that the Chinese students did not give a lot of attention for both language forms as well as written tests. The lack of confidence and desire in using and speaking the language may affect negatively towards learning the language.

Abadikhah and Zarrabi (2011) conduct a study to explore the great effect of push out task on learning verbal morphemes by Iranian EFL learners. To achieve the purpose of the study, two groups of learners from young adult classes. All the participants were male students. Their age ranged from 13-15.Two groups were used in the study. The push out group consisting of 20 learners and a control group consisting of 18 learners. The participants in both groups received pretest and posttest. The findings of the study show that there was a significant difference between comprehension and production of target forms by the learners. Moreover, the results revealed that the push out group and after receiving the treatment outperformed the control group, In addition, the study show that participants in the control group didn't; succeed in showing a clear development in their production despite that they received a measurable gains in comprehending the target linguistic form.

Mehdiand Rahimian (2013) investigates the effects of second language (L2) production on L2 learners' interlanguage (IL) modifications. To achieve the purpose of the study, the researchers compare between English L2 learners' output production and IL modification in performing two different task types, one-way and two-way tasks. The results of the study showed that the L2 learner participants were able to modify their output during negotiation of meaning in both one-way and two-way tasks better than what they had before dong the study.

To investigate the role of push out tasks in developing a target after receiving an input, Basterrechea et al (2014) conduct a study to measure that point. The sample of the study consisted of sixteen adolescent learners from an intact Content and Language Integrated Learning (CLIL) classroom. They were asked to carry carried out a multi-stage dictogloss task in a collaborative and individual form. The researchers follow a certain model to achieve the purpose of the study. The participants carried out different tasks such as listen and jot down key words, and text reconstruction. Then the participants were asked to listen to the text once again in order to compare it with their production. The results of the study revealed that pushed tasks gave the learners the opportunity to notice formal aspects of language in a good way.
Mahmoud abadiet al (2015) conduct a study to examine the effect of push out in presenting the vocabulary tasks and its role in enhancing the knowledge of vocabulary by EFL learners. The sample of the study consisted of $103 \mathrm{el}-$ ementary level. All of the participants were female Iranian EFL learners. The sample of the study was randomly divided into three groups: input-only, input output, and output-input groups. All the participants were asked to take a placement test as well as a vocabulary pretest. To achieve the purposes of the study, the learners in the input group received only input tasks, while the participants in the other two groups received both input as well as output tasks in different sequences. After that, all the participants in the three groups took a vocabulary posttest. The findings of this study revealed that presenting the vocabulary tasks in the sequence of output have a great positive effect for the participants the two push out groups compared with the results of the participants in the group that did not receive any treatment. The positive effect appeared in giving the participants in the push out groups the ability to notice vocabulary knowledge gap and to develop their vocabulary knowledge.

From the above theoretical and empirical arguments, we notice that there are several studies that tried to examine the effect of push out tasks in developing foreign language learning. They indicate that enrolling students in the output activities is considered a useful facilitator to acquire the language and to achieve the native-speakers competence. It is expected that the results as well as the findings of this study can be helpful and beneficial to show that putting learners in real push out tasks will definitely lead to improve and develop their reading performance.

\section{PURPOSE AND QUESTIONS OF THE STUDY}

The main purpose of this study was to investigate the effect of push out in language acquisition that is based on Swain's push out hypothesis (1985) on promoting and developing Jordanian language learners' reading performance.

More specifical y, the study tried to answer the following main question:

1- Is there any significant difference between EFL learners' reading comprehension when they are instructed in push out vocabulary instruction compared to the traditional instructions?

\section{STATEMENT OF PROBLEM}

Al Regeb (2009) confirms that the Jordanian EFL university as well as school students encounter a lot of difficulties when they are asked to read any text, he states that they can't identify the main idea in a reading text, and identify supporting information. They also can't relate what they read to their background knowledge, identify relationships among ideas, draw conclusions from the text, and explain the authors' purpose for writing the text. Al Regeb (2009) and Al Khawaldeh (2011) explain that building vocabulary through reading helps readers to communicate with others. Many students face a lot of difficulties when they engage in reading 
activities due to the lack of vocabulary that they have. This fact is a main factor behind the lack of complete comprehension to the given texts. One may agree that this situation is the same when talking about Jordanian university students.

Another problem is that students as well as teachers do not care about the importance of vocabulary in the process of comprehending texts as reading is a crucial skill in the acquisition of foreign language learning. The amount of comprehension to the text depends mainly on the amount of vocabulary that students know. In addition, a great problem arises when teachers and students do not give a lot of attention to the idea which suggests that exposing students to intensive reading is really a useful and important technique to increase the vocabulary growth among them as it is considered, great facilitator towards a good reading performance.

Moreover, it is believed that few teachers look at the push out hypothesis as a great facilitator to enhance reading comprehension, which also leads to improve the knowledge of English grammar. Furthermore, the researchers have noted that the ability of English language instructors at Jordanian universities is still below the minimum competence of teaching reading adequately as many of them are still using the traditional old techniques in teaching reading activities. As a result, the lack of vocabulary is noted among the majority of students at Jordanians secondary and university students. This fact can be seen from the students' results in the reading tests whether on the national or international level. Swain (1985) states that when learners produce second language, especially when they experience difficulty in communicating their meaning in the L2, they are pushed to modify their output, and as a result the output may increase their comprehension ability.

\section{SIGNIFICANCE AND LIMITATIONS OF THE STUDY}

Since there is a great need to explore the importance of vocabulary knowledge in learning English as a foreign language, it is expected that the findings and the results of this study may provide the university instructors with the necessary insights and recommendations that help in increasing their students' vocabulary knowledge, which leads to improve their reading performance. In addition, it may also shed the light on the importance of push out hypothesis on developing Jordanian university students' reading performance. Moreover, the researchers feel that the findings of the current study could be helpful to the teachers through providing them with the importance of applying some of reading comprehension and assessment strategies and the need to change them to suit the purpose of the reading task. Furthermore, this study is a good opportunity to encourage other researchers to do further studies for other educational levels and on other language skills such as listening, speaking or writing in order to share the results and experience with other instructors. Therefore, the findings of the study may hopefully contribute to the teaching and learning process of English language by shedding more light on the strategies and hypothesis that can be implemented inside the classroom, which may increase our students' comprehension abilities.
The generalization of the results of the study is limited by these factors:

1- The study is limited in the number, gender, and context of students.Only 60 EFL-Jordanian students at ANU who were belonging to Faculty of Arts and Educational Sciences, Department of English Language and Literature, participated in this study in the academic year 2016/2017, 30 in the control group and 30 in the experimental group. So the generalizability of the results of this study is applicable to similar samples only.

2- The duration of the study is limited to the second semester of the academic year 2016/2017

\section{METHODOLOGY}

\section{Research Design}

The present study adopts the experimental design since the main aim is to investigate and examine the effect of push out hypothesis on developing and promoting EFL students' reading comprehension. The assumption in this study was that engaging learners in output activities, would promote their vocabulary development which might enhance the learners' reading comprehension. Accordingly, two research questions were formulated and they were tested and explained in the procedures section. In this study, one experimental group and one control group were selected purposefully. The experimental group received the treatment and strategy based instruction, while the control group did not receive any treatment. Both groups received pre and post test to check the effect of the instruction treatment. In this study, we deal with the independent variable, which is the push out activities task, and the dependent variable is the reading comprehension of both groups -experimental and control groups. This section presents participants of the study, research instruments, statistical analysis, data collection and data analysis procedures.

\section{Participants of the study}

The participants of this study were 60 EFL students at ANU who were chosen purposefully to participate in this study. They were belonging to the Faculty of Arts and Educational Sciences, Department of English Language and Literature. The participants consist of two classes of reading comprehension Course which was published by Macmillan Education LTD, intermediate level. Those 60 EFL participants were divided into two groups, 30 in the control group and 30 in the experimental group. Both groups received a pre-test, and then the researchers started implementing the study. The experimental group received explicit task on using push out tasks, while the control group did not receive any treatment and tasks. After the specific time of the study, both groups received a posttest to check the effect of the treatment.

\section{Instruments}

1- Vocabulary knowledge test

2-A reading comprehension test which is to be used as a pretest and posttest to both: the experimental and the control 
groups, with some modification related to the ways each group is taught accordingly. A multiple-choice reading comprehension test of 30 questions is constructed to assess the students' reading comprehension.

\section{Validity and reliability of the instruments}

To guarantee the validity of the reading test, a jury of TEFL specialists in Jordanian universities were asked to assess the test. To check the reliability of the tests, they were computed on a pilot study of 20 students using the test and retest method. The reliability coefficient was computed using Cronbach's Alpha formula. The value of Cronbach's alpha for pre-test was. 82 and the Cronbach's alpha indicated a high reliability $(\mathrm{r}=.854)$ for the vocabulary pre-test which indicate satisfactory reliability value.

\section{Procedures of the Study}

In order to guarantee the homogeneity of the groups, an achievement reading comprehension test which is to be used as a pre-test to the experimental and the control group was prepared in advance by the researchers. A pre-achievement reading test has 30 multiple -choice questions which are constructed to assess the EFL students' comprehension of the reading text (see appendix A). The researchers chose the reading texts from reading comprehension course, which was published by Macmillan Education LTD, intermediate level (2001).

Then they took vocabulary knowledge test in order to be sure that the participants are homogenous sample (see appendix B). This VKT came to choosing 30 words related to the same reading texts. The average score of each group guarantee the homogeneity. In order to report if the participants are completely unfamiliar with the meaning of some words or items, they were asked to answer the pretest items. In the next step, the researchers employed the push out tasks by giving a list of the 16 unknown words with their definitions in both English and Arabic. This list was handed out to the experimental group. Each week and for one hour, the participants worked on 5 or 6 words along three weeks. These 16 words were introduced through vocabulary activities task by using PowerPoint program (see appendix c) which gave the learners the opportunity to practice using them in different tasks such as teaching by definition and pictures, teaching by context to find the meaning of new words and matching activities. After the treatment, a multiple-choice reading comprehension test of thirty questions was constructed as a post-test to assess the students ' comprehension of the reading text. This post-test was similar to the pretest that is given to both experimental and control groups at the beginning of the experiment with some modification related to the ways each group is taught accordingly.

The experiment, which took place in April of 2017, was summarized as follows:

\section{Detailed overview of experimental procedures}

Control group: (5 min.) Explain Experiment

(20 min) Vocabulary Knowledge Test

(45 min.) Achievement Reading Comprehension Test/pretest
(45 min.)Traditional Way along 3 Weeks

(45 min.) Achievement Reading Comprehension Test/post test

Experimental group: (5 min.) Explain Experiment

(20 min) Vocabulary Knowledge Test

(45 min.) Achievement Reading Comprehension Test/pretest

(45 min.) Pass out new Vocabulary \&Treatments/16 unknown Treatment

Words every week/3 weeks through PowerPoint Program

(45 min.) Achievement Reading Comprehension Test/post test

\section{THE RESULTS AND THEIR DISCUSSION}

To achieve the main objective of the study, the researchers selected randomly two classes from Ajloun National University with 30 EFL students each. The main question was to see if there is any significant difference in the EFL students' achievement in the reading test when they are instructedin push out vocabulary instruction. In order to check the homogeneity of the control and experimental group in the reading comprehension level, their scores in the pre-test were analyzed. So in this study, the researchers used the independent samples T-Test to analyze the possible variances in reading comprehension between the two groups. Table 1 presents the means and standard deviations obtained by the experimental group and the control group on vocabulary pre-test.

\section{Pre Test}

Table one shows that two groups were homogenous in terms of vocabulary knowledge test at the beginning of treatment and instructional tasks since the results revealed that there are not any significant differences $(t=-.127 ; \mathrm{p}>.05)$ between the mean scores of the students in the two groups. Subsequently, the experimental group received explicit task on using push out tasks, while the control group did not receive any treatment or take part in this phase of experiment.

Table 2 presents the means and standard deviations obtained by the experimental group and the control group on reading pre-test.

According to the analysis of the pre-test scores, Table 1 shows that there are not significant differences $(t=-$ $0.74 ; p>.05$ ) between the mean scores of the students in the two groups. This means that the two groups were homogeneous in terms of reading comprehension level before the beginning of the treatment. A list of 16 unknown words with definitions handed out to the experimental group, while the other group did not receive any treatment or take part in this phase of experiment. In order to investigate the effect of push out tasks on the learners' vocabulary knowledge and reading comprehension, both groups were administered reading post-test at the end of the treatment process (see Table 3 ).

Table 3 shows that there is an observed difference between the two means of the students' achievement in the post test due to the received explicit tasks on using push out tasks. The results indicated that the mean scores of the experimental group $(\mathrm{M}=87.72)$ were significantly different $(\mathrm{t}=13.41)$ 
Table 1. Means and standard deviations for samples' vocabulary scores on the pre test

\begin{tabular}{lcccccccc}
\hline Statistics groups & N & M & ST.D & SEM & Mean difference & T & df & Sig. (2- tailed) \\
\hline Control & 30 & 105.33 & 16.53 & 2.648 & -0.433 & -0.127 & 84 & 0.899 \\
Experimental & 30 & 105.77 & 15.08 & 2.200 & & & & \\
\hline
\end{tabular}

Table 2. Means and standard deviations for samples' scores on the reading pre test

\begin{tabular}{lccccc}
\hline Statistics groups & N & M & ST.D & T. test & f \\
\hline Control group & 30 & 68.53 & 4.32 & 0.74 & 0.35 \\
$\begin{array}{l}\text { Experimental } \\
\text { group }\end{array}$ & 30 & 71.75 & 2.61 & & \\
\hline
\end{tabular}

Table 3. Means and standard deviations for samples' scores on the reading post-test

\begin{tabular}{lccccc}
\hline Statistics groups & N & M & ST.D & T. test & f \\
\hline Control group & 30 & 72.32 & 2.35 & 13.41 & 0.14 \\
Experimental group & 30 & 87.72 & 1.76 & & \\
\hline
\end{tabular}

compared to the control group $(\mathrm{M}=72.32)$. Therefore, the pushes out vocabulary activities have contributed to the reading learning comprehension of students in the experimental group.

\section{Discussion of the Results}

From Table 1, one could notice that that there were not significant differences between the students' mean scores in the experimental as well as in control groups in the pre test. This indicates that, the two groups were homogeneous in terms of students' reading comprehension level before the beginning of the experiment. After applying the experiment and after the treatment,one could notice that the experimental group's mean score(87.72) is higher than the mean score obtained by control group(72.32).

It is obviously clear from the table that there were differences between the mean scores of the students in the experimental group and the control group post-test. This indicates that the students in the experimental group performed better than the students in the control group in the reading post-test due to the great effect of using push out tasks and activities that encourage the students in the experimental group to use and produce the language. This leads to a kind of clear improvement for the students in the experimental group as a result to the use of push out hypothesis.

The result of the current paper goes in harmony with studies conducted by Basterrechea et al (2014) who investigate the effect of using the push out tasks for the learners to notice and determine the progress that the learners could achieve after receiving continuous push out tasks. They reveal that push out activities has the advantage to provide EFL learners with a chance to do such tasks easily and effectively. Furthermore, some other studies even found that there are significant role of push out-when presenting some of vocabulary activities to be able to notice the needed lexical items. In addition, it has a great role in helping the learners to improve their vocabulary knowledge of EFL learners(Mahmoudabadi.et al, 2015). They reveal that presentation of vocabulary tasks in the sequence of push out prior to input enhance noticing vocabulary knowledge gap and develop vocabulary knowledge. It may be different from Shekary's study (2004) as it deals with online negotiation, while the current study concentrates on written and spoken negotiation. It is also different from Zhang's study (2009) as his study concentrates on developing the Chinese students' speaking skill while this study concentrates on developing Jordanian reading skill.

\section{CONCLUSION}

The purpose of the current study was to investigate the effect of push out activities in language acquisition that is based on Swain's push out hypothesis (1985) on promoting Jordanian language learners' reading performance. The results of the study revealed that the experimental group's post-test scores were significan ly higher than those of the control group. These results proved that teaching based on Swains' push out hypothesis was successful to develop the students' reading performance.

This paper has shown that students showed progress not only in EFL reading comprehension but also in knowledge of push out tasks. With these tasks and instructions, students were able to develop their awareness in using other reading strategies. Moreover, students' attitudes changed positively toward reading in a foreign language. They gained self-confidence that they could interact with different kinds of readings texts.

\section{REFERENCES}

Abadikhah,S and Zarrabi,F. (2011).The Effect of Output Tasks on the Acquisition of English Verbal Morphemes. Theory and Practice in Language Studies, 1(11), 15491560.

Al Regeb,K.(2009).The effect of semantic mapping and group discussion on Jordanian secondary stage students' reading comprehension and verbal communication in English. Unpublished Phd. Dissertation. Amman Arab University. Amman. Jordan.

Al-Kawaldeh, A. (2011). EFL reading comprehension interest among Jordanian high school students and their relationship with gender, achievement level and academic stream. European Journal of Social Sciences. (3):454-465

Anderson, R. C., \& Freebody, P. (1981). Vocabulary knowledge. In J. Guthrie (Ed.), Comprehension and teaching: Research reviews (pp. 77-117). Newark, DE: International Reading Association. 
Basterrechea et al (2014). Pushed Output and Noticing in a Dictogloss: Task Implementation in the CLIL Classroom. Retrieved March 13,2017 fromhttp://www.ugr.es / portalin/articulos/PL_numero22/1\%20\%20Maria $\% 20$ Basterrech

Gass, S. M. (1997). Input, Interaction, and the Second Language Learner. Mahwah, NJ: Lawrence Erlbaum Associates, Publishers.

Hu Hsueh-chao, M. \& Nation, I.S.P. (2000). Unknown Vocabulary Density and Reading Comprehension. Reading in a foreign language, 13(1),403-30.

Izumi, S.(2002).Output, input enhancement, and the noticing hypothesis. Retrieved March 15,2017 from https://www. researchgate.net/publication/231781443 Output input enhancement_and_the_noticing_hypothesis.

Izumi, S., \& Bigelow, M. (2000). Does Output Promote Noticing and Second Language Acquisition? Tesol Quarterly, 34(2), 239-278. http://dx.doi.org/10.2307/3587952.

Izumi, S., Bigelow, M., Fujiwara, M., \& Fearnow, S. (1999). Testing the output hypothesis. Studies in Second Language Acquisition, 21(3), 421-452.

Krashen, S. D. (1980). The input hypothesis: Issues and implications. In J.Alatis (Ed.),Current issues in bilingual education (pp. 144-158). Washington, D.C.: Georgetown University Press.

Kowail, J., \& Swain, M. (1994). Using collaborative language production tasks to promote students' language awareness. Language Awareness, 3(2), 73-93.

Laufer, B. (1992b). Reading in a foreign language: How does lexical knowledge interact with the reader's general academic ability? Journal of Research in Reading, 15(2), 95-103.

Laufer B. and Sim, D.D. (1985). Measuring and explaining the reading threshold needed for English for academic purposes texts. Foreign Annals, 18(5), 405-411.

Leeser, M. J. (2008). Pushed output, noticing, and development of past tense morphology in content-based instruction. Canadian Modern Language Review, 65, 2: $195-220$.

Long, M. (1996). The role of the linguistic environment in second language acquisition. In W. C. Ritchie \& T. K. Bhatia (Eds.), Handbook of second language acquisition (pp. 413-468). New York: Academic Press.
Mahmoudabadi.et al (2015). The effect of sequence of output tasks on noticing vocabulary items and developing vocabulary knowledge of Iranian EFL learners. International Journal of Asian Social Science, 5(1), 18-30.

Nagy, W., \& Herman, P. (1987). Breadth and depth of vocabulary knowledge: Implications for acquisition and instruction. In M. McKeown \& M. Curtis (Eds.), the nature of vocabulary acquisition (pp. 19-35). Hillsdale, NJ: Erlbaum.

Nagy, W., Herman, P., \& Anderson, R. C. (1985). Learning words from context. Reading Research Quarterly, 20(2), 233-253.

National Reading Panel (2000). Teaching children to read: An Evidence-Based Assessment of the Scientific Research Literature on Reading and Its Implications for Reading Instruction. Washington, DC: National Institute of Child Health and Development.Report of the National Reading Panel. Washington, DC: National Institute of Child Health and Human Development.

Pica, T. (1994). Research on negotiation: What does it reveal about second-language learning conditions, processes, and outcomes? Language Learning, 44(3), 493-527.

Rahimian, Mehdi. (2013). Negotiation of Meaning and Modified Output Elicitation across Two Tasks. English Language Teaching, 6 (12), 114-128.

Shekary, M. (2004). Negotiation of meaning and noticing in cyberspace: The role of text-based on-line chat in the development of SLA. (Unpublished MA thesis). University of Isfahan, Isfahan, Iran.

Swain, M. (1985). Communicative competence: some roles for comprehensible input and comprehensible output in its development. In S. Gass \& C. Madden (Eds.) Input and Second Language Acquisition. Rowley, MA: Newbury House.

Swain, M. (2000). The Output Hypothesis and beyond. In J. P. Lantolf (Ed.), Sociocultural theory and second language learning (pp. 97-114). Oxford: Oxford University Press.

Wilkins, D.A. (1972).Linguistics in Language Teaching. Australia: Edward Arnold.

Zhang,S. (2009). The Role of Input, Interaction and Output in the Development. English language Teaching.2(4), 91-100. 


\section{APPENDIX A}

\section{Vocabulary Knowledge Test}

Name:

Academic No.(..............)

\section{Choose the best substitute for the underlined words in the following sentences:}

1-The plane flew so high that it seemed we were touching the roof of the world.
a. low covering
b. top covering
c. inner edge
d. center

2-The house's rural setting is sure to attract many buyers.
a. countryside
b. urbane
c. cultured
d. city-born

3-The grassy plain stretched for miles in all directions.
a. polluted
b. contaminated land
c.floral lan
d. flat lan

4-The aim of our current urban renewal plan is to do away with all those old slums.
a. countrified are
b. rural area
c. city area
d. pastoral area

5-The explorers planned an expedition in order to map the river.
a. organized journey
b. short journey
c. unorganized journey
d. normal voyage
6- Illiteracy is a huge problem in developing countries.
a. ability to read
b. inability to read or write
c. ability to draw
d. ability to sing

7-The Japanese company exports new cars to Asia and Africa.
a. buys goods
b. imports
c. sends for sale
d. keeps

8-The manager of the bank asked the employees to carry out many duties at the week end.
a. do
b. delete
c. delay
d. record

9-Brian's pension isn't huge, but it's enough for him to live on.
a. yearly payment
b. retirement salary
c. weekly payment
d. daily payment

10-Th US imports a lot of gas from other countries
a. exports
b. buys
c. sells
d. stores

11- Sara has a visual memory.
a. faint
b. unnoticeable
c. optic
d. equivocal

12- My father said a thing today about life which has been in my thoughts a good deal, and you make me recall it
a. forget
b. remember
c. block
d. defend

13- Yes, Miss Patty," and though Jane's eyes fle wide open, she made no verbal comment.
a. oral
b. written
c. uncommunicative
d. numerical

14- Perhaps John was not a very emotional man.
a. impassive
b. cool
c. stolid
d. passionate

15-The psychologist advices us to train our memories to keep them strong.

a.an expert in sociology

b.an expert in biology

c.an expert in studying mind

d.an expert in studying nature 
16- Like others, Salma had fallen a victim to her grey eyes.
a. casualty
b. winner
c. fi hter
d. boxer

17- And you really are in sympathy with these women?
a. cruelty
b. dislike
c. compassionate
d. selfishnes

18-When people start forgetting everything in their life, psychologists call this state "amnesia".
a. losing weight
b. losing money
c. losing memory
d. losing control

19-Many of our vocabulary are going to fade, if we do not use them in our daily conversation.
a. acquire slowly
b. lose quickly
c. acquire quickly
d. increase slowly

20- Ali tried his best to recover his health well after the car accident that happened to him last year.
a. recuperate
b. deteriorate
c. lose
d. waste

21-The aircraft landed safely in the airport yesterday.
a. departed
b. went away
c. left
d. came down

22-The road slopes gently to the sea.
a. goes quickly
b. goes slowly
c. goes hardly
d. goes smoothly

23- He sat on the chair, swinging his medal.
a. swaying
b. stopping
c. climbing
d. freezing

24- Many Jordanian farmers use the ladder in doing some of their agricultural affairs.

a. a piece of equipment made of wood

b. a piece of equipment made of clay

c. a piece of equipment made of ice

d. a piece of equipment made of soil

25- The boy was about to descend from his little horse when he heard his father's asking him to stay on the horse.
a. come down
b. arise
c. climb
d. dive

26-The hunters saw a giant pear in the forest last week.
a. small
b. huge
c. tiny
d. small

27- How do you purpose to accomplish this job?
a. fail
b. achieve
c. abandon
d. give up

28-A woman plunged to her death from the cliffs at Beachy Head yesterday.
a. went suddenly
b. jumped carefully
c. went slowly
d. reached slowly

29- Many Asian tourists decided to make an exploration along the African Nile river to discover its beauty.

a. travelling to unknown places

b. travelling to known places

c. travelling to the pole

d. travelling to the equator

29-A sudden wind stirred the apple leaves.
a. stopped
b. moved
c. destroyed
d. collected

30 -He deposited $€ 20$ a week into his saving account.
a. got
b. saved
c. took
d. gave 


\section{APPENDIX B}

\section{Reading Comprehension Test}

Name:

\section{Q.1: Read the following text and then answer the questions that follow. (10 points)}

The roof of the world -Nepal. Nepal is one of the remotest countries on earth. It lies to the north of India and the world's highest mountain, the Himalayas; separate it from Tibet, which is part of china, to the north. The population of Nepal is around 20 million. Most people live in rural areas, either in mountain valleys or on the wide plain to the south. The majority are farmers.

The official language of Nepal is Nepali. Around half the population speaks this as a first language, but over fifty other languages and dialects are spoken. The Nepalese consist of several different peoples. The most famous are Sherpas and Ghurkas. The Sherpas provide guide and porters for mountaineering expedition - both men and women can carry heavy loads long distances. The Ghurkas have for a long time been famous as soldiers in the Indian and British armies.poor health is a major problem in Nepal. Another is the high rate of illiteracy, currently around 79\%. Only 5\% of the population over 15 could read or write and malaria was widespread in Tarai. Now it is much reduced and this has encouraged many people to move there. Nepal mainly trades with India. It exports agricultural produce such as wheat, rice, herbs and spices, but it has to import essential goods such as petrol and metal. The communications are poor and there are few rail way or hard surfaced roads.

1- Why are more people able now to live in the Tarai?
a. Malaria was widespread in Tarai.
b. Malaria is much reduced in Tarai
c. The high rate of illiteracy.

2- What is the major problem in Nepal ?
a. The high rate of illiteracy among people
b. The poor health for people
c. The great number of languages used there

3- What does Nepal export?
a. Petrol and metal
b. Gold and silver
c. Agricultural products

4- The sentence which shows that a big number of the Nepalese could not read and write is:
a. "the high rate of illiteracy, currently around 79\%".
b. "Only $5 \%$ of the population over 15 could read or write".
c. "people live in rural areas, either in mountain valleys or on the wide plain to the south".

5- People who live in Nepal are:
a. Sherpas and Ghurkas
b. Farmers
c. Indians

6- Why is it difficult for many farmers to sell their goods in India ?
a. It is one of the remotest countries on earth
b. The communications are poor and there are few rail way or hard surfaced roads.
c. It is a poor country

7- Find a word in the text which means "flat open land"
a. paraffi
b. aid
c. Plain

8- the underlined pronoun it, line (1) refers to:
a. Country
b. Nepal
c. Roof

9- The word" illiterate" means:
a. Educated
b. can read and write
c. cannot read or write 
10- One word that could replace "the majority "
a. Few
b. Most
c. Minor

Q.2: Read the following text and then answer the questions that follow. (10 points)

Some people say they have no memory at all, but of course we all have a memory.Our memory tells us who we are. Our memory helps us to make use in the present of what we have learnt in the past. In fact we have different types of memory. For example, our visual memory helps us recall faces and places. Some people have such a strong visual memory; they can remember exactly what they have seen.

Our verbal memory helps us remember words and fi ures we may have heard but not seen written. With our emotional memory, we recall situations or places where we had strong feelings, perhaps of happiness or unhappiness. We also have special memories for smell, taste, touch, and sound.

We have two ways of storing any of these memories. Our short - term memory stores items for up to thirty seconds- enough to remember a telephone number while we dial.Our long-term memory, on the other hand may store items for a lifetime. Older people in fact have a much better long-term memory=than short one.

Psychologist tell us that we only remember a few facts about our past and that we invent the rest. It is though we remember a few only the outlines of a story. We then make up the details. Psychologists are not certain how or why we forget. Maybe memories simply fade away if they are not recalled. Another theory says fresh materials replace memories. Sometimes people lose their memory completely. This is called amnesia. Suddenly they do not know who they are not even their names, where they live, or their families. Sometimes they recover from this illness, regaining all or some of their memory. How wonderful never to forget anything, but in fact we need to forget. If we remembered all our unhappy times, we would become mentally ill.

1- There are different types of memory:
a. Visual,verbal and emotional memories
b. Long and short term memories
c. Good and bad memories

2- When you accidently pick up in the dark an unknown object that feels very cold and wet, the memory that is used called:
a. Visual memory
b. Verbal memory
c. Emotional memory

3- We often remember wrongly because:
a. Memories simply fade away if they are not recall.
b. Memories are constantly replaced by fresh material.
c. We only remember few facts about our past and that we invent the rest.

4- Forgetting is as essential as remembering because:
a. If we remembered all our unhappy times, we would become mentally ill.
b. Memories are constantly replaced by fresh material.
c. We want to appear as heroes of our own past.

5- There are two ways of storing many kinds of memories:
a. Long and short term memories
b. Good and bad memories
c. Verbal and visual memories

a. One word that could replace "all the time"
b. Rarely
c. Constantly
d. Regularly

6- The underlined pronoun "they", line (4) refers to:
a. people
b. short memories
c. long term memories

7- Amnesia is
a. losing part of the memory
b. losing the memory completely
c. illness that people will never recover from 
8- A person who studies the mind is called a:
a. doctor
b. psychologist
c. biologist

9- A word that means "accept as a true":
a. assume
b. need
c. look at

Q.3: Read the following text and then answer the questions that follow. (10 points)

On the $20^{\text {th }}$ July 1969, the Lunar Module 'Eagle' landed gently on the sea of Tranquility. 'Eagle' stirred moon dust that had lain undisturbed for millions of years. Edwin 'Buzz' Aldrin radioed mission control: 'The Eagle has landed.'

'We're breathing again-thanks a lot' was the replay from Mission Control. Some time later, the door of the module swung slowly open and a ladder descended. American Astronaut became the first human being to walk on the surface of the Moon. Billions of people worldwide heard his famous words: 'That's one small step for a man, one giant leap for mankind.

The two astronauts spent two and a half hours on the Moon. Their first task was to collect rock samples. Then they set the United State flag and filmed one another leaping around. There is no wind on the Moon, just as there is no water, so the flag had to be spread with hidden metal support. Next they deposited a box of messages sent by world leaders

On The Moon, the force of the gravity is much lower than on earth. This means you can jump six times higher. But just walking can be difficult. The astronauts found the easiest way to move around was by kangaroo hops.

Meanwhile Collins, the third member of the crew, orbited the Moon in the Command Module. Their mission accomplished, Armstrong and Eldrin reentered the Lunar module. 'Eagle' lifted off the moon and rejoined the Command Module.

When they were safely aboard, the Lunar Module was jettisoned, and the Command Module returned to earth. With heat-shield blazing and traveling at nearly $11 \mathrm{~km}$ a second, it plunges through the Earth's atmosphere. The air slowed down the descent. Then parachutes opened so the module could land gently into the sea, where a recovery ship was waiting. This was the first Apollo mission. In the next three and a half years, five more crews voyaged to the Moon, collecting samples and preforming scientific experiments

1- The Sea of Tranquility is:
a. On the moon
b. In space
c. On Earth

2- The two astronauts who were walking on the moon spent:
a. Two hours
b. Two and half hours
c. Three and half hours

3-You can jump six times higher on the moon than on the earth because:
a. Walking is more diffic lt on the moon
b. The force of gravity is much lower on the moon than on earth
c. The force of gravity is much higher on the moon than on earth

4-The module landed into the sea because:
a. The air slowed down the descent.
b. A recovery ship was waiting there
c. It was more safely

5-"Jettisoned"means:
a. Fastened securely to the Command Module
b. Detached from the Command Module
c. Command Module returned to the earth

6- Their main task on the moon was:
a. To discover the secrets of the universe
b. To perform scientific e periments
c. To collect rock samples

7-The underlined pronoun "their" line (16)refers to
a. People
b. Two astronauts
c. Neil Armstrong and his colleague 
8- One word that could replace "descended"
a. Put down
b. Get rid of
c. Come down

9-The Eagle landed on the moon in:
a. 1969
b. 1978
c. 1979

10-The United State flag had to be spread with a hidden metal support because

a. There is no soil

b. There is no water and wind

c. There is no atmosphere

\section{Teaching Vocabulary}

